\title{
Citigroup's John Reed and Stanford's James March on management research and practice
}

\author{
Academy Addresses Edited by Anne Sigismund Huff
}

\begin{abstract}
Academy President's Executive Overview
One of my most pleasurable, though daunting, jobs as president of the Academy of Management in 1998-99 was to select the Distinguished Scholar and Executive of the Year. I was lucky enough to find two people who have been in conversation for some time about an issue that deeply concerns me. In my presidential speech, which will appear later this year in the Academy of Management Review, I outline changes in the way knowledge is being created-both in academic disciplines and in companies. I think these changes are changing the nature of business schools, and potentially jeopardizing their future. James G. March and John S. Reed have had similar concerns for some time. The following article summarizes some of their conclusions.
\end{abstract}

John Reed, the Academy of Management's 1999 Executive of the Year, is co-chairman and CEO of Citigroup, the result of the October 1998 merger between Citicorp and Travelers Group. It is the largest financial service company in the United States, with over 100 million members, and assets over $\$ 600$ billion. With the largest share of credit card business in the U.S., Citigroup has particular potential in e-commerce. I was also especially pleased that John Reed accepted our invitation because of his enduring interest in social and behavioral science. He is a member of the Corporation of MIT, as well as the board of the Center for Advanced Behavioral Sciences in Palo Alto, and the Spencer Foundation in Chicago. He is also on the board of the Philip Morris Companies Inc., Monsanto Co., and the Spanish telephone company, Telefónica.

James March, the Academy's 1999 Distinguished Scholar, convinced John to accept our invitation. Jim's outstanding career is hard to summarize. Organizations, with Herbert Simon, A Behavioral Theory of the Firm, with Richard Cyert, and Leadership and Ambiguity, with Michael Cohen, are just three examples of work on organizations and decision making that strongly influenced me and many other members of the
Academy of Management. Jim has just retired from four joint positions at Stanford University-in management, political science, sociology, and education-but his research agenda continues. I look forward to reading The Pursuit of Organizational Intelligence, which came out in 1999, and The Dynamics of Rules, which will be published in 2000 . He has eight honorary doctorates, and a long list of other honors to place beside our selection as 1999 Ácademy of Management Distinguished Scholar.

The following pages record the presentations that our two honorees gave at the 1999 Academy of Management meetings in Chicago. Jim March briefly sketches out the history of the pursuit of ideas in management practice and management research, then comments on the risk of business schools' becoming too concerned with "relevance." John Reed draws on his banking experience to argue for the importance of basic research from business school academics. They conclude with a conversation about the Council he established to facilitate academic research in Citicorp. I think their reflections are important and well argued. Beyond that, they illustrate an important source of management ideas-conversational engagement 
between those in business schools and those in business practice.

\section{Distinguished Scholar of the Year James G. March}

Historically, and I think currently, some of the most influential contributors to knowledge and writing about organizations have been deeply involved with questions about management practice. Many of them have been practicing managers. I include such contributors as Gluck, Urwick, Barnard, Drucker, and Peters, each of whom have been important to our understanding of management. There has also been a tradition of academic research in organizations, research carried out by people somewhat less directly linked with management practice-people like Weber, Simon, Selznik, and Williamson.

The two streams of writing generated by such authors have affected each other. It is not so much that the writers have learned from each other, although they have done a little bit of that; it is more that they have existed together in a loose community of common concern within which both streams have had influence. But they remain relatively independent, responsive to different pressures, different incentives, and different institutions. On the one hand, there has been a community of management practice organized around the culture of managers and management consultants. On the other hand, there has been an academic community organized around the culture of academic disciplines, traditions, and institutions. One of the glories of business schools in this country and the institutions associated with them, including the Academy of Management, is the way they have brought these two groups together in a productive association of relatively tolerant mutual appreciation.

It is, however, an uneasy relationship. The differences in orientation, styles, and cultures produce tension. They also produce dynamism. The tension, however, makes maintaining a fruitful balance between these two streams difficult. It is an old story. The pressures of day-to-day adapta-

The differences in orientation, styles, and cultures produce tension. They also produce dynamism.

tion are intolerant of the diversities that serve adaptation in the long run. Tension between these two streams is essential to the health of the field, but the opposition that sustains the tension also tends to destroy it. The groups struggle for dominance in a world in which neither can exist long without the other. As a result, there is a tendency toward grand swings.

\section{Changes in Business School Orientation}

Business schools have been the site of a lot of that tension. Their history is one of continually renegotiating the relative emphasis placed on the one hand upon managerial practices as a source of ideas, and on the other hand upon academic research as a source of ideas. Though it is clear that many of the more enduring ideas about organizations are well grounded in each tradition, up until the end of the Second World War, business schools were essentially purveyors of business practices. Their faculties were drawn for the most part from experienced business managers and people linked to them. Business schools had relatively little standing within academic communities. They were ranked largely by their reputation in business.

Beginning about 1950, however, business schools turned to an increased emphasis on academic research based on academic disciplines. They substantially increased the fraction of academically trained faculty and writing directed to academics. They substantially increased the academic reputation of business schools, and the use of academic criteria to establish the reputations of their scholars.

Recently, we have seen movement back toward the dominance of practice, and the elevation of business practice to a higher pinnacle of importance as a basis for knowledge. This is part, of course, of the general public endorsement of business practice. It is connected in a general way to the acceptance of markets as instruments of allocative decision making. It has certain curiosities which I will not pursue in any depth, though I occasionally tell my business friends that one of the curiosities of modern life is that we are insistent on introducing the methods of business to higher education and to the public sector, two sets of American Institutions that have been conspicuously and internationally successful in the past few decades, much more successful than American business has been as a whole. That is an unfair observation, of course, but it is intended as a reminder that our enthusiasms are sometimes more dependent on ideology than on evidence.

During this period we have transformed business schools. Beginning in the 1980s and continuing into the 1990s, there has been an increasing tendency to make management research in business schools more immediately relevant to business practice. The quality rankings of business 


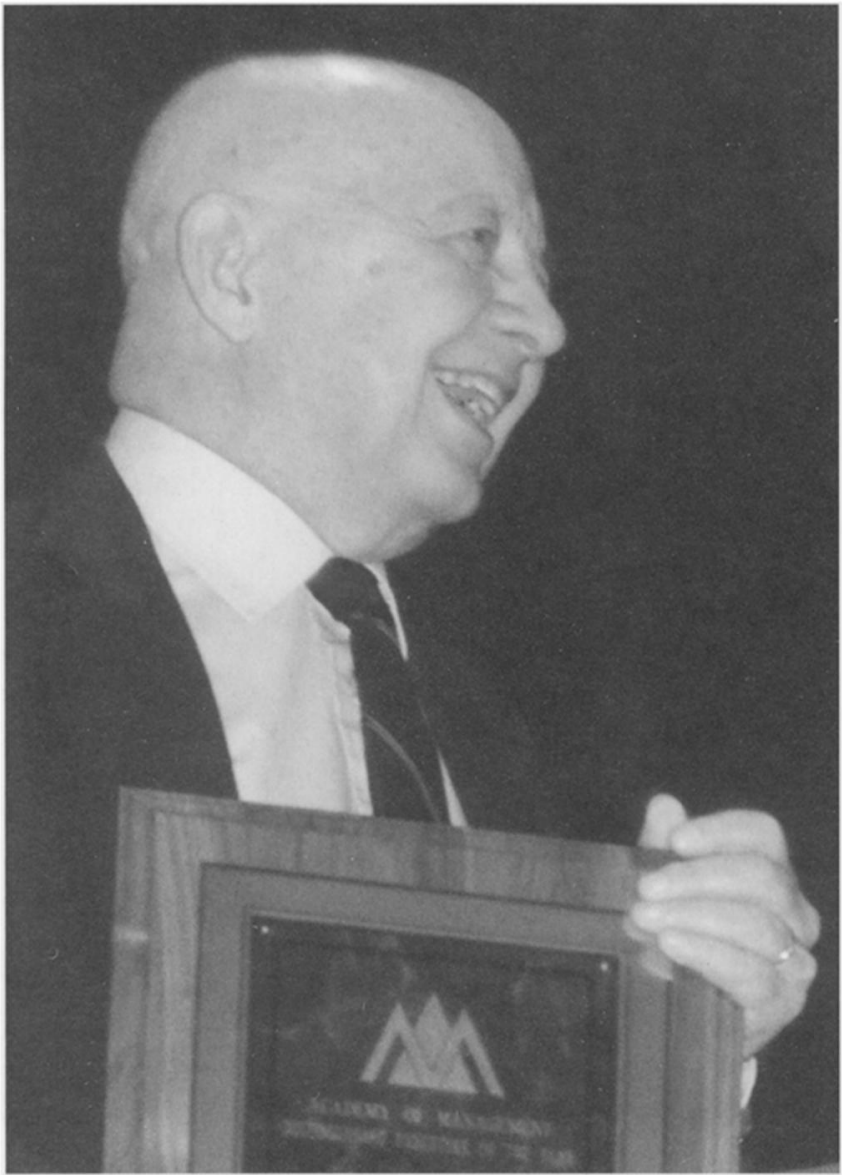

James G. March

Distinguished Scholar of the Year

schools, which were previously dominated by academic self-rankings that emphasized the research reputations of the faculty, have been captured by the business press with rankings that place very little emphasis at all on the quality of research as assessed by academic standards. Management researchers in business schools are clearly increasing in numbers, but they are also increasingly publishing their research papers in journals associated with business schools, participating primarily in professional associations connected with business schools, and increasingly isolated from researchers in other disciplines. They define themselves increasingly as being concerned with improving management and business strategy rather than adding to knowledge.

If you have not read it, I invite you to read a piece in The New Yorker on July 19, 1999 by James Atlas. Atlas provides what is probably accurately described as an advertising brochure for the Harvard Business School, and, by extension, other business schools in the United States and Europe. It is a blurb remarkably similar to those produced by other business schools. Atlas frames his essay as an answer to the question: "Does the business world really need business schools?" I think it is a reasonable and interesting question. Atlas, of course, having framed it, never addresses it. But he is clearly extremely positive about the Harvard Business School and, by extension, business schools in general. He pictures them as providing a socializing function for entrance to business that is oriented to serving the personal economic interests of students.

More specifically, here is what he says about the Harvard Business School: It is very rich, and operates from a high-cost facility, including luxurious offices and an expensive information network. It admits only a small fraction of people applying for the MBA. It is demanding on its students. To its graduates it provides contacts and credentials useful for getting ahead. (A little footnote, there is no mention in this article about any provision of substantive knowledge.) Its graduates receive salaries that "tend to start in six figures and go up from there." It is in step with the market. Thus, it is represented in the Silicon Valley by its own offices and by graduates from unusual backgrounds who are getting rich in entrepreneurial jobs rather than in big corporate jobs. It charges high fees and produces for sale a large number of cases that are used by other business schools. These cases typically begin like a feature story in a magazine and go on to encourage the sense that management is an active sport. It emphasizes having faculty who are consultants and former executives, who although they put teaching into a "money machine," are nonetheless dedicated and evangelical.

This article is an extremely positive portrayal in its own terms. Its tone is upbeat and positive. The picture is one of $\alpha$ vital social institution confronting the turbulence of modern life and adapting to it successfully. The business school is pictured as a partner in the American economy, and as sharing the wealth that economy is generating.

But Atlas's portrait is one of a knowledge-free and research-free business school. It places almost exclusive emphasis on the linkage between management practice and business schools, emphasizing the hiring of faculty with management experience, and the credentialing and contact-forming function of management education. Unless you define case writing as research, and the writer clearly does not, the description gives no role to research or research-based knowledge in business education, either as a basis for knowledge or as an activity for business schools. 


\section{The Misguided Search for Relevance Rather than Knowledge}

The Atlas article is not important. I assume it was not entirely innocent of marketing intent. But it is representative of a trend. It portrays a movement toward viewing business schools as credentializing and contact-forming institutions, of value primarily to students who want to secure good positions in business. That is not an unworthy vision, but it is a vision with consequences for the development of ideas about management. It is based on a view of knowledge as coming primarily from experience. This orientation is, of course, supported by many people both in and outside of business schools. For example, it is supported by many business people and business school administrators. It is an orientation that makes it easier for business to assess and make use of business school faculty and students, places greater control over business schools in the hands of business institutions, and places greater control over the faculty in the hands of academic administrators.

It is not, however, a vision supported by everyone, and I am one of those non-supporters. Of course, I should disqualify myself. I am an unreconstructed resident of the ivory tower. I went to school when I was five years old, discovered I liked it, and I stayed. I spent most of my life in professional schools, thriving on having students who wanted a different life from mine, and on conversations with business, military, public, and educational managers. But for many years I have begun every class that I have taught with the assertion: "I am not now, nor have I ever been, relevant." In some sense I really do not believe that. But I do not believe it is anything that I want to spend time defending or addressing. Given that attitude, I am likely to misconceive the appropriate balance between experiential knowledge and research knowledge, and thus misperceive the current situation. But I do not think I misperceive it too badly.

I think the recent headlong pursuit of immediate relevance in business schools and in management research is wrong. Both the pressure toward relevance and the acquiescence to it are misguided. The main advantage of an academic institution can be found in academic research and its contribution to knowledge. It is not in trying to identify factors affecting organizational performance, or in trying to develop managerial technology. It is in raising fundamental issues and advancing knowledge about fundamental processes affecting management.

What in management research is important for management practice? If we look historically, at least when I look historically, it is not the passing fads of management gimmicks. It is not the numerous studies attempting to relate performance to one thing or another. It is the basic ideas that shape the discourse about management-ideas

\section{I think the recent headlong pursuit of immediate relevance in business schools and in management research is wrong.}

about conflict of interest, problems with information and incentives, bounded rationality, diffusion of legitimate forms, loose coupling, liability of newness, dynamic traps of adaptation, absorptive capacity, and the like.

There are reasons why researchers should focus on basic research. The comparative advantage of fundamental knowledge over experiential knowledge goes down the closer you come to concrete, specific situations. If you are in a situation in which a manager has experience, you should not expect an academic to be terribly helpful. In those situations, managers are likely to know best. The context makes a difference, and experience is a good teacher of context. However, the comparative advantage shifts as you move to more novel situations. It shifts to academic knowledge, to general knowledge, to fundamental knowledge. Fundamental knowledge becomes more useful to managers (in combination with context-specific experimental knowledge) in changing worlds, in new ventures, and when faced with the unexpected. Researchers who pursue immediate relevance are likely to produce knowledge that is both redundant with what managers already know, and useful only over a limited time and under limited conditions.

Unfortunately, we are engulfed in a contemporary enthusiasm for immediate relevance. That enthusiasm is not new, and the reasons we attend to relevance are salutary, but our enthusiasm has become excessive. It is an enthusiasm that I believe threatens to make business schools and management research minor contributors to the development of ideas about business management and organizations, condemned to the role of pursuing short-run research on questions of minuscule importance, contributing little to intellectual life and therefore to business life. In the long run, if business schools cease to be effective as intellectual institutions, they will not thrive as economic institutions.

Even if that were not true, our more important obligation as scholars is to the pursuit of knowledge. In particular, we can maintain a significant role for significant research on management by recognizing two fundamental principles. The first 
principle is that a commitment to research is a commitment to knowledge, not to immediate results. Research is a calling, not a job. The second principle is that practicing managers are not stupid. They recognize or can be led to recognize that the primary usefulness of management research lies in the development of fundamental ideas that might shape managerial thinking, not in the solution of immediate managerial problems.

\section{Executive of the Year John S. Reed}

\section{Introduction by James March}

If any proof is needed that managers are not stupid, John Reed provides it. John is a U.S. citizen who grew up in Argentina. He went to MIT for a bachelor's and a master's degree. He went to Citibank, discovered he liked it, so he stayed. They decided they liked him, so they promoted him.

John has talked to my class for a number of years. When he first came, he was a wunderkind. He was the young, new, dynamic executive who was going to lead us out of the forest. The students crowded around him, and they cheered, and they told me, "This man is a genius-a great man."

John came again two years later. At that time, according to the Wall Street Journal, he was about to be fired: Citicorp was in deep trouble, nothing he did was working, he was inadequate for the job. He came and talked about exactly the same things. He talked exactly the same way. He had exactly the same style. He had exactly the same ideas. He didn't change, but the students saw a totally different person. They saw someone who was pretentious, who was not really modern, was not really up to it, probably a little stupid.

Then another two years went by, and John came back again. By that time he was a savior. He had turned Citicorp around and the stock prices were going up at a precipitous rate. He was the newfound international wonder boy, and students flocked. He was exactly the same, had the same style, said the same things. Now, however, he was brilliant. He was outstanding.

This history has some implications. Certainly for John, I suspect. It also has some implications for student judgment, and why we cannot be too attentive to immediate assessments of relevance.

I think that John is an extraordinarily talented manager, but he is more than that. He has a deep commitment to knowledge. He has served on the Russell Sage Foundation board. He served on the Center for Advanced Behavioral Sciences board. $\mathrm{He}$ has been actively involved with the Santa $\mathrm{Fe}$ Institute, and he is here. You may think being here is not much, but I will tell you that I saw John in California early last week. Between then and now he has been in Mexico, Argentina, and Venezuela. He arrived here early this morning, and he will be in London tomorrow. So being here is no trivial thing. He is one of us, and I'm proud to have him here as Executive of the Year.

\section{A Practitioner's View of Management}

Thank you very much, Jim, for your kind words. Let me be very honest. I am really here because I love being here. I look forward to the opportunity to get out of the day-to-day, to sit back and try to understand what is going on with the practice of management and what is going on in the research community. It allows me some breathing room and gives me a sense of what it is that I have been spending the last 34 years doing.

I am going to comment on the practice of management and the research agenda, but very much from the point of view of a practitioner. As Jim indicated, I joined Citibank over 30 years ago, for lots of strange reasons, few of which have had anything to do with the company. Lo and behold, to my surprise, and maybe to theirs, 34 years later I am still here. Not only that, but as many of you know, we have just gotten ourselves into a big merger, and one would guess I am going to be here for a while, because there is much on the agenda.

I thought I would draw on this experience of mine as a practitioner, as somebody who has cared a lot about the practice of management and who has tried to understand just what it is we are trying to do and how it is that we do it. I will add to Jim's comments by talking about this business we are in from my point of view and drawing on my own experience. Hopefully it will turn out to be relevant to your own concerns about what is going on in the academic enterprise and the role that a research agenda plays within that enterprise.

\section{The Importance of Long-Term, Evolutionary Company Success}

Let me make some introductory points. First, I think I represent my colleagues who run big companies. If you are a banker, you get to know most of the people running the big companies around the world because they are your customers. Obviously, understanding them and their business is important to you, and so in addition to my own job, I am an observer of those who have similar kinds of jobs in various businesses around the world.

I think it would be fair to say for most of us, whether we would verbalize it this way or not, that 


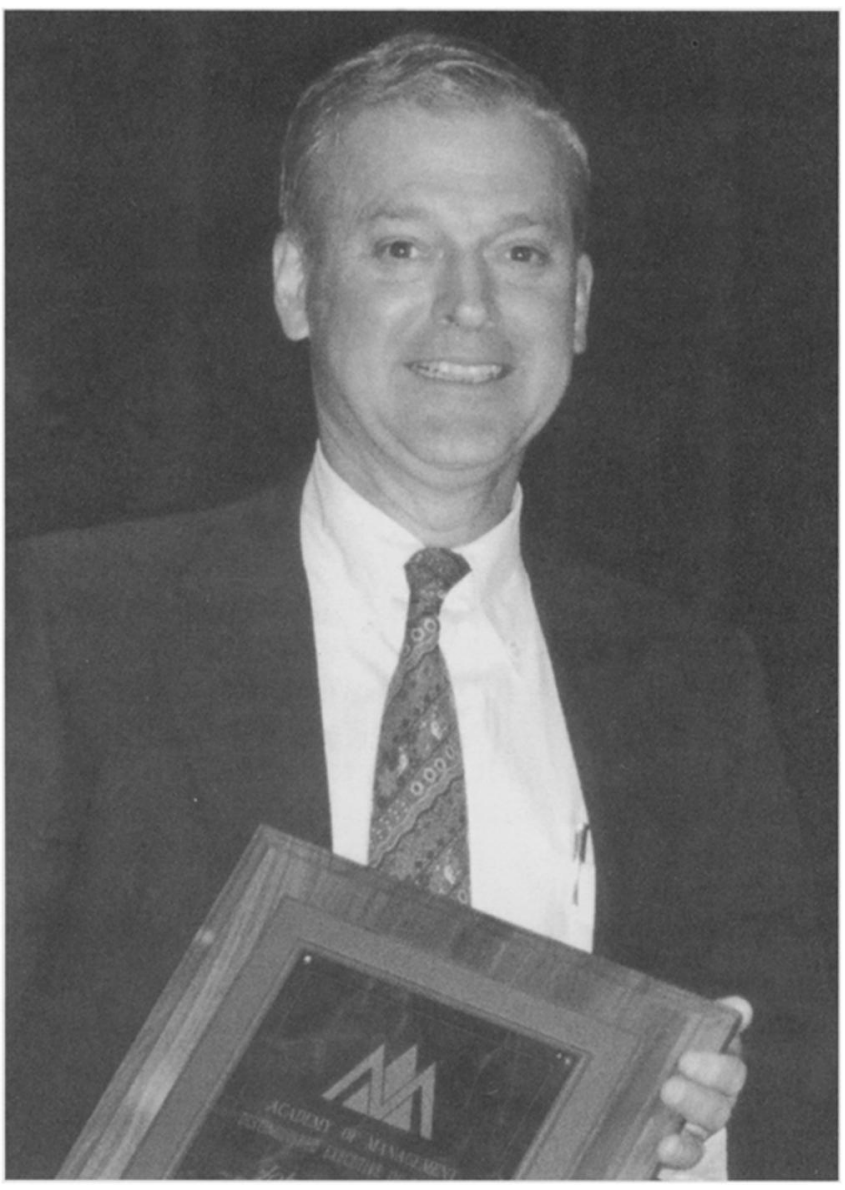

John S. Reed

Executive of the Year

our objective in running our business is the longterm, evolutionary success of the firm. I mean that we try to improve the opportunities that our companies face over time as we shape those companies and as we drive them toward performance. The opportunities we describe are broadly defined. They can be opportunities for growth in revenue, for improved returns, for positioning in new markets. For example, without any question the biggest single risk and opportunity facing the banking business today is the Internet and what it is going to do to how we conduct our business. Our objective, however, is long-term, evolutionary success. We try to be in a situation of continually improving opportunities and we try like mad to avoid getting into dead ends.

I would argue that profits and price earnings on stock and things of that sort are significant and important contributors to our evolutionary success, but they are insufficient in and of themselves. Having a model of business that stops at the word profit is problematic. Most of my colleagues and I have come to understand that profit is not a robust model and that we need, in fact, $\alpha$ broader vision of what it is we are trying to do. We are concerned about improving the opportunity space for our enterprise. Profits and value in the stock market and return on equity and so forth are important, but we have any number of stories of great, profitable companies that have reached bad endings rather quickly, and so we have gone beyond that.

\section{Most of my colleagues and I have come to understand that profit is not a robust model and that we need, in fact, a broader vision of what it is we are trying to do.}

This basic observation is a challenge to the academic enterprise. It defines the nature of business practice more broadly than a simplistic economic model might, particularly in microeconomics, where agents are presumed to simply be profit maximizers. There is an additional dimension.

\section{The Importance of Effectiveness}

You might ask, "OK, you are a business person, what is it that you have to do?" I am of the school that says we have to do two things: we decide what to do, and we try to make it happen. If you boil down all of the practice of business, it is the combination of those two things and the interaction between them that defines the world in which we live.

Obviously your ability to make things happen has a direct feedback effect on what it is you might aspire to do. When you are younger and starting out, you tend to be much more concerned with making things happen and making use of tools and techniques that you have either observed or learned that might convert action into output. As you move up in an organization, you spend more and more time trying to decide what to do. You get it wrong, and you get it right, and it is not easy. But basically we are all in the business of figuring out what we should do at any given moment in time and developing mechanisms and techniques to make things happen.

At this point in time, I sense that businesses increasingly are pushing on the envelope of organizational performance. We all seem to be butting right up against the frontier of effectiveness. Our ability to operate within the organization seems to be the constraint. You can see that if you look at some of the great success stories that people turn 
to these days, and try to understand them. Take General Electric, for instance.

I know GE reasonably well, and I know Jack Welch quite well. I think most people would not say that the great success of the General Electric Company is its strategy. Most people would say that the great success of that company has to do with execution, with the fact that Jack, in conjunction with his seniors, has driven organizational performance of the General Electric Company far beyond expectations. They have a bunch of fundamentally uninteresting businesses like power generation and phones, and yet they have been able to create a company which over an extended period of time has sustained impressive performance and which commands a very high multiple in the market. Even though they engulf a bunch of businesses that frankly are not that exciting, are not that modern, and do not enjoy particularly exciting, sustainable growth. Yet they have been able to convert that enterprise into a very high performing one because they have learned, and they have institutionalized, mechanisms by which they can take their company right to the frontier of performance.

The Japanese taught us during the 1980s that they could do better than Americans thought possible. When you started peeling the onion, it turned out to be organizational effectiveness and the ability to get workers to more effectively bond with their jobs within a Japanese enterprise that seemed to be the distinguishing characteristic of those firms. Americans have learned that, have copied that, and have moved it on.

I spent sometime recently in Silicon Valley trying to get my mind around the Internet and its implications for my own business. I was struck by what I am sure is going to be a revolution that will have a dramatic impact on the way in which customers interact with the total sense of businesses. But I was equally impressed by the quality of the people I met, their energy, and the seeming organizational effectiveness of people working in Internet companies.

I wonder if the ability of these enterprises to command the interest of such high quality people, who seem to have come up with new organizational configurations that allow them to be quite effective, differs importantly from more established firms. I wonder if that dynamic is going to turn out to be as important to the evolution of the business enterprise as the potential of the Internet itself. Be that as it may, I think that in the practice of business we are pushing right on the envelope of organizational performance. We are looking for ever more effective ways of causing organizations to function effectively.

\section{Research Contributions to Improving Effectiveness}

The academic community has helped define the current circumstances of business. It can also help open doors to possible future levels of performance that we do not fully understand at this point. Being a non-academic, I will undoubtedly describe the academic community and its contributions with a slightly different twist than you might, but as I look at the academic enterprise I divide it into two groups.

One group makes use of case studies which really are nothing but best practice. They look for patterns of behavior that seem to produce success, or patterns of behavior that seem on average not to produce success, and then draw more general conclusions from this. There is also an awful lot of work going on that looks across industries. Both approaches allow practitioners to see what others have done, and see what has seemingly worked and not worked.

Practitioners can draw some primitive conclusions from this work. If you see that somebody else has been able to achieve something that you have not, it clearly gives you the courage and drive to make it happen. That is important in business because, as I said, deciding what to do is our primary task, and having the courage to reach for some goals that you might otherwise have thought to be unobtainable is clearly very valuable.

The academic community is not the only source of such insight. Consultants do similar things very well. And of course the world seems to consist of nothing but managerial how-to books these days, some of which I find to be quite insightful, though I would not characterize the great majority that way. These activities also move from best practices to generalized conclusions, move from observable patterns of behavior to outcomes, and do a good job of packaging the results so that they are available to practitioners.

A second group of academics stands farther back and draws from the disciplines to get a better sense of what is going on. My own experience over the years has been that this latter school tends to be more useful than the first group because it creates $a$ framework that allows practitioners to understand how to locate the specific business problems that we may be dealing with within a broader space.

Think, for example, about the usefulness of research on careers. There is no question that the way in which people in the U.S. today are shaping their careers has changed. Having some understanding of what is going on would give managers new insight into how we might shape our own 
activities to attract the kinds of people we want to have. Incentives are undoubtedly critical. We go nuts in the business world trying to incent behavior. Frankly, we do not know as much about how to do that as we would like. I would guess that the

\section{We go nuts in the business world trying to incent behavior. Frankly, we do not know as much about how to do that as we would like.}

wastage is quite significant and the opportunity for incentivizing poor behavior is at least as high as the opportunity for incentivizing good behavior.

We need the opportunity to stand back from our immediate concerns to get some sense of what the research community has learned about incentives. Learning itself is another arena of great interest to the business community. There is an awful lot of learning that takes place throughout a business career, and like it or not, we are in the business of teaching people. It would be useful for us to have some understanding how to be more effective at that. It would also be useful to know when in various careers learning plays different kinds of roles.

These issues come from $\alpha$ broader research agenda than best practice summaries. My sense is that interaction between the more idea-based research community and the practicalities of specific business problems like the ones I just mentioned can be the more productive from a practitioner point of view. I do not mean to make light of the development of certain mathematical models and tools. Clearly, their development has been extremely important, particularly in the banking business. We do a lot of training through simulation. We are in the business of managing risk. Some of the tools and mathematical models that have been generated in the academic community clearly underpin $\alpha$ lot of our thinking. I still believe that when it gets down to core business problems, it is the intersection between a broader theory and the specifics of our own problems that produces the best sort of insight.

\section{Examples of Needed Research}

Let me start to develop the idea that broader, more basic, research agendas are needed by touching on things that involve my own career. The first thing that happened to me when I became chairman of Citibank back in 1984 was that it took about one day to figure out we had a fundamental problem because of international defaults. If you will recall, in the fall of 1982 Mexico had suspended payment on its debt, and we were in the process of coming to grips with what became known as a Latin America or even a global cross-border debt problem. Citibank at the time had $\$ 4.7$ billion in capital and about $\$ 16$ billion of exposure in these heavily indebted countries, and it didn't take much arithmetic to identify a major issue.

The first thing that I had to confront as chairman was to figure out just what the heck this mess was, and what we had to do about it. Let me tell you that there was very little that I learned at the Sloan School that was immediately useful. This was a question of getting my hands around what was clearly a global problem. It was a problem very much being defined by the Federal Reserve, by the IMF, and by private sector banks. The banks were led mostly by Citibank, because we were both the most experienced globally and the most involved globally. All of a sudden, I had to stand back and try to get my mind around the nature of this problem, what likely exclusions might look like, and how my own institution, as well as the banking sector in general, might deal with this problem.

I had a professor at Harvard give me tutorials during this period so that I could understand more about the history of prior debt crises, and the functionality and usefulness of the IMF. It seemed to me, as a practitioner and somebody with a very direct responsibility in figuring out how to resolve this problem, that I had to be on very firm ground with regard to understanding just what a broader view of the problem might say about the likely patterns that would lead to a solution.

We spent the better part of eight years working on this problem. I would say in retrospect that it came to an extremely satisfactory conclusion, in the sense that the banking systems survived, in the sense that the countries survived, and probably were to some degree improved by the experience. I do not want to get too carried away, however, because there was a lot of economic damage to the global system.

Citi also survived and prospered afterwards, which, if you believe in long-term evolutionary success, says we found satisfactory answers to the two questions of what to do and how to make it happen. Some of our colleagues interpreted this experience as "No more of this, thank you very much," and so the experience also shaped the evolutionary pathway of participants who today have chosen not to participate in this business. In our case, it pushed us the other way. We stayed in the business and are today still deeply embedded in the potential of emerging markets. Academic research is part of that success. 
It was pointed out earlier that I am on the board of both Philip Morris and Monsanto. These are interesting companies that I can also draw on to highlight areas where business practice can benefit from research. Philip Morris is a very large publicly traded company worth more than $\$ 100$ billion in the market. When somebody comes and says, "Gee, you are in the cigarette business, why don't you just close down the company?" it is hard if you were elected by the stockholders to reply, "Well, we'll rip up $\$ 100$ billion of market value and that's too bad if it was your investment, we'll start all over again."

Obviously, you have a dilemma here which is a fundamental problem and you have to figure out if there is an appropriate space towards which you might move. I will tell you that we on the board were the people who said to the company, "We've got to find a solution other than through litigation." We felt that we had to reach out, to try to figure out what society felt comfortable with: with regard to cigarettes, health issues and other things. We had to understand that as humans none of us deals with bad news easily. If you have been in a business for a long, long time and somebody comes to you and says, "Your business creates great harm," the first thing you do is not believe it, and then you get angry, of course, and very defensive. But then the third thing, assuming you get over those feelings, is that you begin to get your mind to run.

That is when basic research would be helpful. Someone says, "We have a lot of statistical evidence that says people who smoke are more vulnerable to various diseases." But it is very hard to get your hands on what to do about statistical evidence, even though it may in fact be true. Because there is no mechanism. It is not as if somebody comes and says, "This particular chemical in your product is causing harm." If that were to happen it would be very easy to say, "Fine, we'll remove that chemical from the product." Indeed, if you go to Virginia you will find a couple of thousand acres owned by Philip Morris with one single plant in the center, a plant that extracts all of the chemicals from tobacco. The plant was built with the thought, which has not materialized, that somebody was going to some day tell them that there was a specific chemical which, if removed, would solve the problem, and then they would be able to go back and see what was left of their product.

Of course, no one has been able to identify a cause and effect between the product and health problems. They have simply been able to see the statistical correlations. As directors, you cannot just say to the stock owners, "Too bad, there went
100 billion bucks." You have to figure out how to manage this enterprise in a space that is not defined by things that you learn in simplistic case studies. You are out in the real world. You are out in the world where, as a director, you have to recognize that the management of the company is going to be slow to come to grips with the problem for a lot of very human reasons.

You can see that the board has a particular role to play because we are not as engaged in the day-to-day, and therefore, presumably we bring a somewhat different vantage point. You are talking about social policy. There is no one in America who wants to prohibit cigarettes, because we learned through Prohibition that that does not produce great results, and yet there is no one in America who wants cigarettes to be sold as easily as you would sell gum. There is some middle ground and the question is how to find it, how to evolve towards it and how to try to reach some kind of settlement.

I toss that out as a real-world example and suggest to you that the research community has a lot to offer people who are trying to deal with these kinds of problems. It is the insight from more fundamental research, in behavioral systems, in government-societal relations, in human values and economics, and in other areas that is informative. All that research can do is inform us. It certainly does not give us answers. It informs us with regard to what an appropriate type of behavioral response might be.

\section{All that research can do is inform us. It certainly does not give us answers. It informs us with regard to what an appropriate type of behavioral response might be.}

Now Monsanto, on whose board I also sit, is beginning to run into similar problems. Monsanto is in the business of genetically modifying plants to improve their effectiveness and their performance. They have used the new sciences of biotechnology to do what basically used to be done by crossbreeding. They have been extremely effective and have a pipeline of potential products that look like very important products to the agricultural community and the global community, including very large numbers of undernourished people around the world. And yet, there is, particularly in Europe but not only in Europe, considerable concern about the impact that genetically modified products might have on the human population. 
Once again, you are stuck with the problems of how to fit your business system into societal values. Once again, these are business problems that are key to the development of whole new industries, and yet they require a set of understandings not easily pulled out of a how-to-manage-yourcompany kind of book. We must rely heavily on accumulated knowledge and wisdom drawn broadly from the fields of sociology and psychology, economics, political science, and so on, to understand how to cope with such problems.

A fourth example from my own career involves the Citigroup merger. Citicorp decided about $\alpha$ year and a half ago to merge with Travelers, because both Sandy Weill and I felt that by merging we would significantly improve the likely opportunities faced by our two companies, as contrasted with what might happen to us independently. I must say, a year and a half later, that both Sandy and I would agree 100 percent that the opportunities we saw in fact are there. If anything, the wisdom of the merger is even more compelling than at the time we first talked about it. But let me tell you, making a merger work is a totally different story.

We are talking about putting two cultures together that are quite different, quite distinct. There is a lot of literature out there and I've been reading it, because I am trying hard to understand how to make this work. I will tell you that it is not simple and it is not easy and it is not 100 percent clear to me that it will necessarily be successful. Just as the body can sometimes reject an organ that it needs, business systems can sometimes reject behaviors that are required for the system's success. As you put two cultures together, you get all sorts of strange, abhorrent behavior, and it is not clear whether each side getting to know the other side helps, or whether having common objectives helps, or whether it is just the passage of time.

Just as the body can sometimes reject an organ that it needs, business systems can sometimes reject behaviors that are required for the system's success.

I will tell you that the literature on putting together two families speaks volumes to me. The problems of stepparents, the descriptions of some children rejecting one parent, and other children rejecting other parents, and all of the children being generally ticked off, is all meaningful. The Travelers people are ticked off that they did the merger, because clearly these Citi people are a bunch of idiots, and why did we ever have to go into business with them? And the Citi people are equally annoyed. Sandy and I both have the problem that our "children" look up to us as they never did before, and reject the other parent with equal vigor, saying "Sandy wouldn't want to do this, so what do I care about what John wants." Trying to put together one of these mergers brings out $\alpha$ whole set of problems that again leads us to reach back and lean on a set of insights from a much broader research agenda. I would urge you, in the academic community, to bring your particular understanding to bear on what happens during that year, year and a half, two years after merger.

We are trying to do something, by the way, that is truly a merger. Sandy and I are joint CEOs; each basically has a veto over the other. He and I get along fine. That does not mean we have figured out how to run the company well, but it is very different from an acquisition where there is a clear dominant voice. In a true merger, you really have to put together two groups, probably much like integrating a school. When schools first became integrated in this country, I am reasonably certain that the classroom situation must have been very difficult for the teachers. Integration is not something that just happens automatically.

Of course, both the press and a certain number of people in the company would rather not have it be a merger at all, but a power struggle. I think people would prefer to shift from the difficulty of putting together two cultures to thinking about $a$ power struggle. Frankly, they would feel more comfortable in a power struggle and more secure interpreting likely outcomes, than in a merger where what you really have to do is change. You have to be willing to say, "Hey, I will no longer do things the way I used to do them. I'm going to find new ways of doing things that are some kind of amalgam of the way I used to do them, and the way we've decided to do them in light of the opportunities that we are now dealing with."

There is a lot of literature about power struggles, but not enough written about the alternative to power struggles. The willingness of people to change is limited, and what you pay them seems to be inversely correlated with their willingness to change. I used to believe that once you paid people some of these astronomical salaries that we currently pay, you would have mature, self-sufficient, self-confident individuals on your team. Let me assure you, it is not the case. Once again I would reach back to the theme that Jim and I are trying to develop. The research community needs to provide big ideas; these are the concepts that have the most to say to practitioners in the business world who are trying to change their companies. 
If the academic community, for reasons of simplicity or whatever, were to move away from the tradition of standing back and trying to develop big ideas and instead get caught up in trying to generate short-term techniques, summarize best practices, or make other interpretations of business problems, we will lose some of the dynamism that has characterized the U.S. private sector. I believe the private sector has benefited tremendously from the fact that there was a research base out there informed by economics, psychology, sociology, political science, studies of leadership, and so on-knowledge about human beings.

We now are at a point where understanding who humans are, how they respond to opportunities, and what they dream about is essential to business practice. We are well beyond engineering studies, and simple time and motion studies that give us insight as to what a production function looks like and how it might be managed. We have taken the practice of business in this society and globally well beyond the mechanical. We are out dealing with issues that require the presence of $\alpha$ broader understanding. It is not something you could generate just by being a management consultant and observing a number of companies; you have to draw on some of the core knowledge that we have put together over the centuries.

My sense from a practitioner's point of view is that maintaining the balance between core research and applied research is as important to us as it is to the academic enterprise. The business community knows full well that business schools perform a useful function sorting potential hires, but I wonder whether the business community really believes that what happens during those two

\section{My sense from a practitioner's point of view is that maintaining the balance between core research and applied research is as important to us as it is to the academic enterprise.}

years in business school is all that important. The schools sort out from the general population those who are more ambitious, more energetic, more willing to subject themselves to two years without income and endure a certain amount of intellectual harassment in order to say they graduated from a business school. But the real question is: do you give these students a set of skills that is going to serve them well over their careers? On average, clearly the answer to that is yes. Are we maintaining the quality of that endowment? Is the value added from those two years as good today as it was 15 or 20 years ago? That is not as clear.

\section{Conversation on Management Research in Business}

James March: John, four or five years ago you created something called at that time the Citicorp Behavioral Sciences Research Council. I thought that it would be helpful if you said what was in your mind when you did that. What kinds of constraints were there? What do you think it has accomplished or could accomplish? And what would make it better?

John Reed: I had been on the Board of the Russell Sage Foundation for a while and more generally involved with social and behavioral science research activities. There were 168,000 people in Citigroup in 100 countries. I was struck by the fact that researchers seemed to know an awful lot about what is going on within society, while we did not have the same degree of insight as to what was going on within this society called Citigroup. Indeed, we weren't 100 percent sure of what was going on at the border between Citigroup and the outside world. And so I had the notion that we might attract some academic research interest in understanding what was going on within, at the time, Citibank and Citicorp. In the back of my mind, I also had the notion that if this turned out to be a useful enterprise, I might be able to convince some of my other colleagues who run big companies to join me, a step that we have not yet taken.

Basically, what I did was commit \$1 million a year for 10 years, so there would be some clear funding. I said we would be willing to use this money to support any research that passes two tests: one was that it has to be academically acceptable; in other words, it has to meet an academic standard that is no different than that which the Russell Sage Foundation would demand of a research proposal, to use an example I am familiar with. And secondly, the research proposal had to benefit from the fact that it was centered within Citibank or Citicorp. That meant that we had to be willing to make available any and all information from within the company and we could put no restrictions on publication.

Needless to say, my lawyers told me that we shouldn't do this, but I am very much of the opinion that if we are doing something that is fundamentally illegal or evil, I would rather find out about it myself rather than have somebody else find out about it. Therefore, if some academic were to stumble upon some horrible illegal practices on the part of the company, I was willing to run that risk. 
We have for the last three or four years been funding research projects that fit into that scope. They tend to be involved in organizational issues, some of them with regard to motivational issues. For example, we have a great study going on as to whether or not you can economically justify the notion of hiring people who are referred to you, in contrast to people who have not been referred to you. Frankly, those of us running the company do not know how we make the decisions as to who we hire, and therefore the insight that we could gain on how the system actually works is important. We say that we are an equal opportunity employer, and in theory we are, but we have never taken $a$ look to see if, in fact, we really are. How do we make these decisions? Who makes them? How are the rest of us informed? These are the kinds of questions we cannot answer.

In any event, we created new capability with the Council. It has been functioning now for about four years, and my impression is that we are batting 30 to 40 percent. I am sure that we have not attracted the interest of every academic that we would like to attract. We clearly have funded some studies that have disappointed both the people involved, as well as ourselves. But I would also say that we have attracted some studies that have turned out to be quite useful, and I am hopeful that this will continue. Unfortunately, the research community missed our merger to a large degree. I like to be sitting up in a corner watching this thing take place, because there is a lot going on that no one appears to understand.

March: I gather a couple of things. This operates more or less as a research foundation, and the people who review proposals are, for the most part, very well known academics-people like Jane Dutton, Bob Gibbons, Jim Baron, ah, and yes, I. But also John Reed. Our discussion of proposals reveals a side of John that you will not find in most executives, or at least I never found in most executives. John thinks about these proposals about the way academics do. I do not think that I have ever heard you say, John, "Now, will this help Citicorp?" I have often heard you say, "Will this contribute to knowledge?" In the early days we had a fair number of applications of people who wanted to be consultants. We collectively said that is not what the Council is all about. We are about doing research and we want to know how a proposal ties into some fundamental questions. I think we've done fairly well. Thirty percent is probably pretty close.

But I am interested, John, in why you think every other business executive in the country has not jumped to join with us?
Reed: I think that it is hard for most business practitioners to stand back. Business gets a lot of attention now, and for whatever reason, society has sort of turned business into sport. We now have magazines devoted to the play of the week, the team of the day and so forth. But the reality is that business is hard work. Most of the people who get engaged in business get tremendously engaged in getting things done within the particular context of their own business activity. Most, certainly not all, but most CEOs are inherently curious and well-read people. Typically, they are very well-traveled, and exposed to many dimensions of life. But the academic community can seem distant and not relevant to the immediate sort of concerns of these people, and so there is a gulf, there is a cultural barrier.

My sense is that there are people who are likely to join us if this endeavor becomes easier. Then it will be easier to get another company to say, "Hey, I'll make my company available as well." Companies have a lot of data about what is going on within them. We can create data, and create databases that can be sustained over time. When somebody wants to do a longitudinal study, it is possible for us to create the conditions that will allow you to do that. Which is awfully hard to do in the academic world. My sense is that we will get some other business enterprises to join in this, but not all. For whatever reason, we are perfectly willing to have a census of the whole community every ten years, but not every practitioner feels comfortable in having the census of the company's people taken, even though there is a lot we could all learn about what is going on within our own shop.

March: Well, John, as you pointed out, your lawyers were not all wildly enthusiastic about this initially. Have there been any problems?

Reed: Never. Occasionally we find things that should not be happening, and that is fine. We correct them. As I said, none of us running big companies these days wants to run companies that are doing anything that is inherently evil. So if you are studying hiring practices and as a byproduct of that you discover that they are less than they should be, frankly, we are better for your having discovered it. Yes, you have created documentation that might allow somebody to sue us, but if you had not discovered it, we would have continued the bad practices, and sooner or later we would have gotten sued anyway. And so my general feeling is that if we are doing something that we should not be doing, I would just as soon find out about it, pay up, and keep going. 
March: Do you have any reaction from your HR people?

Reed: I think the HR community has found it stimulating. There are two views of the HR community. One view is that they cut paychecks and distribute them. This is not my view. If I had to choose one function within the company that I would like to be most effective it would be HR.

What the HR community has found is that basic research has allowed them to stand back and ask a lot of questions that are quite germane to how the company evolves and what kind of internal culture we have.

If I had to choose one function within the company that I would like to be most effective it would be $H R$.

I mentioned that the way business needs intersect with changing career patterns and firm needs is important. Twice a year, we bring younger people together for a one-month study on issues that we are concerned with. We call it "team challenge," and did one recently about life-work balance. We discovered to our immense surprise that there was an undercurrent within the company that was global-this was not a U.S. phenomenon, this was a global phenomenon. There was tension with regard to our culture versus the need to have a normal human life with kids and family and so forth. Our HR community understands full well that we have to understand work-life issues better, we have to have an understanding of changing career issues, and we then have to link all of this to the kind of environment we create within the company.

We pay out billions of dollars a year in wages. $A$ very significant portion, I would say at least a third of it and maybe more, is supposedly performance- based incentives. We really are uninformed by any robust knowledge with regard to how we pay out that money. We have routines and we have bonus processes and we get the right people in the right rooms talking about the right things. But as an observer over an extended period of time, I would be astounded if we were coming any place close to the mark. You wonder whether the creation of cultures that makes money so central to the endeavor might have second-order effects that are worse than the thing you are trying to do. This is a real HR issue and the HR community is willing to come in touch with researchers to look at the world from a different point of view.

March: With these attitudes, John, why aren't you a professor?

Reed: I have enjoyed my business career because we're pushing right to the frontiers. We make some mistakes, and I have learned $\alpha$ lot that has caused me to appreciate the real need to maintain academic research capability. I also must say that I have enjoyed getting some insight into the academic world and some of the issues you all deal with. We need to keep talking.

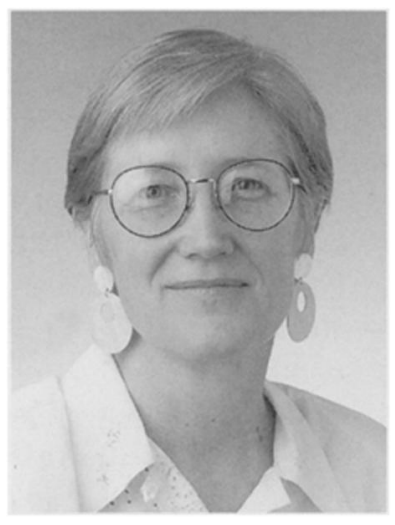

Anne Sigismund Huff is professor of strategic management at the University of Colorado, Boulder, with a joint appointment at Cranfield School of Management in the U.K. She received her Ph.D. from Northwestern University. Her research interests focus on strategic change. She is the author of Mapping Strategic Change (Wiley, 1990). In 1998-99 she was president of the Academy of Management. Contact: Anne.Huff@Colorado.edu. 